\title{
Erratum: $Q_{\mathrm{EC}}$-value determination for ${ }^{21} \mathrm{Na} \rightarrow{ }^{21} \mathrm{Ne}$ and ${ }^{23} \mathrm{Mg} \rightarrow{ }^{23} \mathrm{Na}$ mirror-nuclei decays using high-precision mass spectrometry with ISOLTRAP at the CERN ISOLDE facility [Phys. Rev. C 100, 015502 (2019)]
}

\author{
J. Karthein $\odot,{ }^{*}$ D. Atanasov, K. Blaum, M. Breitenfeldt, V. Bondar, S. George, L. Hayen, D. Lunney $\odot$, V. Manea $\odot$, \\ M. Mougeot, D. Neidherr, L. Schweikhard, N. Severijns, A. Welker, F. Wienholtz, R. N. Wolf, and K. Zuber
}

(Received 10 February 2020; accepted 9 March 2020; published 6 April 2020)

DOI: 10.1103/PhysRevC.101.049901

In our original publication concerning the $Q$-value determination for the ${ }^{21} \mathrm{Na} \rightarrow{ }^{21} \mathrm{Ne}$ and ${ }^{23} \mathrm{Mg} \rightarrow{ }^{23} \mathrm{Na}$ mirror-nuclei decays, the ionization energy was not included. The $Q$ values of the presented $\beta$ decays, hence, change by $17 \mathrm{eV}$ in the case of ${ }^{21} \mathrm{Na} \rightarrow{ }^{21} \mathrm{Ne}$ and $3 \mathrm{eV}$ in the case of ${ }^{23} \mathrm{Mg} \rightarrow{ }^{23} \mathrm{Na}$. The essence of the paper, namely, the calculated $\mathcal{F} t$ values and the resulting $V_{\text {ud }}$ element of the CKM-quark-mixing matrix are not affected due to dominating uncertainties in the other relevant quantities. Equation (4) in the original publication now reads

$$
Q_{\mathrm{EC}}=(r-1)\left(m_{\mathrm{ref}, \mathrm{lit}}-m_{e}\right) c^{2}+r E_{\mathrm{i}, \mathrm{ref}}-E_{\mathrm{i}, \mathrm{IOI}},
$$

with the literature mass for the reference atom $m_{\mathrm{ref}, \text { lit }}$, the electron mass $m_{e}[1]$, the speed of light $c$, and the ionization energies for the reference atom and atom of interest, $E_{\mathrm{i}, \text { ref }}$ and $E_{\mathrm{i}, \mathrm{IOI}}$ respectively. As a result, Table I is modified to:

TABLE I. Summary for ${ }^{21} \mathrm{Na}^{+}$and ${ }^{23} \mathrm{Mg}^{+}$showing the number of Ramsey-type spectra taken, the estimated production yield at ISOLDE, the half-lives [2], the reference ion for cyclotron frequency ratio determination, the measured cyclotron frequency ratio $r$, and the measured $Q_{\mathrm{EC}}$ values using ionization energies from the National Institute of Standards and Technology [3] in comparison with the ones published by Low-Energy Beam and Ion Trap (LEBIT) for ${ }^{21} \mathrm{Na}$ [5] and by TRIUMF Ion Trap for Atomic and Nuclear Science (TITAN) for ${ }^{23} \mathrm{Mg}$ [4].

\begin{tabular}{|c|c|c|c|c|c|c|c|}
\hline Isotope & $N_{\text {spectra }}$ & Yield $\left(\mathrm{s}^{-1}\right)$ & $T_{1 / 2}(\mathrm{~s})$ & Reference & Ratio $r$ & This erratum & Literature \\
\hline${ }^{23} \mathrm{Mg}^{+}$ & 19 & $1 \times 10^{8}$ & $11.317(11)$ & ${ }^{23} \mathrm{Na}^{+}$ & $1.0001894144(15)$ & $4056.179(32)$ & $4056.35(16)$ \\
\hline
\end{tabular}

Based on the 17- and 3-eV changes in the $Q$ values, Table II is updated to:

TABLE II. Calculated vector part of the statistical-rate function $f_{\mathrm{V}}$, mirror-nuclei $\mathcal{F} t^{\text {mirror }}$ value, and the $V_{\text {ud }}$ element of the CabibboKobayashi-Maskawa matrix for ${ }^{21} \mathrm{Na}$ and ${ }^{23} \mathrm{Mg}$. For details, see the text.

\begin{tabular}{lllll}
\hline \hline Isotope & \multicolumn{1}{c}{$f_{\mathrm{V}}$} & $f_{\mathrm{A}} / f_{\mathrm{V}}$ & $\mathcal{F} t^{\text {mirror }}(\mathrm{s})$ & $V_{\text {ud }}$ \\
\hline${ }^{21} \mathrm{Na}$ & $170.714(6)$ & $1.0170(17)$ & $4071(4)$ & $0.9715(34)$ \\
${ }^{23} \mathrm{Mg}$ & $378.51(2)$ & $1.0195(20)$ & $4724(14)$ & Not available \\
\hline \hline
\end{tabular}

We thank W. J. Huang for bringing the discrepancy to our attention.

\footnotetext{
*Corresponding author: jonas.karthein@ cern.ch

Published by the American Physical Society under the terms of the Creative Commons Attribution 4.0 International license. Further distribution of this work must maintain attribution to the author(s) and the published article's title, journal citation, and DOI.
} 
[1] S. Sturm, F. Köhler, J. Zatorski, A. Wagner, Z. Harman, G. Werth, W. Quint, C. H. Keitel, and K. Blaum, Nature (London) 506, 467 (2014).

[2] G. Audi, F. G. Kondev, M. Wang, W. Huang, and S. Naimi, Chin. Phys. C 41, 030001 (2017).

[3] A. Kramida, Y. Ralchenko, J. Reader, and NIST ASD Team (2019), NIST Atomic Spectra Database (version 5.7.1) [Online: 2020, February 8].

[4] B. E. Schultz, M. Brodeur, C. Andreoiu, A. Bader, A. Chaudhuri, U. Chowdhury, A. T. Gallant, A. Grossheim, R. Klawitter, A. A. Kwiatkowski, K. G. Leach, A. Lennarz, T. D. Macdonald, J. Lassen, H. Heggen, S. Raeder, A. Teigelhöfer, and J. Dilling, Phys. Rev. C 90, 012501(R) (2014).

[5] M. Eibach, G. Bollen, M. Brodeur, K. Cooper, K. Gulyuz, C. Izzo, D. J. Morrissey, M. Redshaw, R. Ringle, R. Sandler, S. Schwarz, C. S. Sumithrarachchi, A. A. Valverde, and A. C. C. Villari, Phys. Rev. C 92, 045502 (2015). 